\title{
RAPID SCREENING OF TANNASE PRODUCING MICROBES BY USING NATURAL TANNIN
}

\author{
Arijit Jana, Chiranjit Maity, Suman Kumar Halder, Bikas Ranjan Pati, Keshab Chandra Mondal, Pradeep Kumar Das \\ Mohapatra*
}

Department of Microbiology, Vidyasagar University, Midnapore - 721102, West Bengal, India.

Submitted: August 28, 2011; Returned to authors for corrections: October 20, 2011; Approved: June 07, 2012.

\begin{abstract}
Use of natural tannin in the screening of tannase producing microbes is really promising. The present work describes about the possibility and integrity of the newly formulated method over the previously reported methods. Tannin isolated from Terminalia belerica Roxb. (Bahera) was used to differentiate between tanninolytic and nontanninolytic microbes. The method is simple, sensitive and superior for the rapid screening and isolation of tannase-producing microbes.
\end{abstract}

Key words: natural tannin, Bahera, tannase, plate screening, enteric yeast

Tannin acyl hydrolase (E.C: 3.1.1.20), generally known as tannase, hydrolyzes tannin (a plant constituent) to yield glucose and gallic acid. A diverse group of bacteria and fungi can synthesize tannase as on required basis $(2,9,10,13)$. At present, tannase is used in different industrial sectors, mainly, for preparation of gallic acid, instant tea, acron wine, coffee flavoured soft drinks, high-grade leather tannin, clarification of beer, fruit juices, etc. $(3,5,6)$. Gallic acid, a hydrolytic product of tannin, has different uses like preparation of trimethoprim (bacteriostatic antibiotic), pyrogallol and propyl gallate (14). Recently, it has also been reported that tannase producing bacteria are associated with advanced stage in the colon cancer, allocating the possibility of bacterial tannase as a biomarker for colon cancer (17). In respect of its usefulness, potent tannase producers are fewer as reported throughout the world (20). The fact behind their less population is that tannin itself is toxic for the microbes which retard their growth $(4,16)$. So they become harmful at the initial stage of isolation process. Instead of commercial tannic acid (used till date at each screening process), a correct choice of alternative tannin type like natural tannin may solve the problem raised at the basic level of screening process.

Osawa and Walsh (18), Kumar et al.,(12) and Mondal and Pati (15) reported about tannase screening but all of these methods are time consuming and less sensitive which have made these limited towards specificity determination and the isolation and screening of bacteria. That is why, in the present investigation, an alternative effort has been taken to develop a rapid, more sensitive, visual and easier screening method for detection of tannase producing microorganisms including bacteria, yeast and fungi, so as to assist the isolation process.

All the chemicals used in this study were of analytical grade and procured from Himedia, India and Merck, India. Tannase producing two bacterial (Bacillus sp. PAB2 and Bacillus licheniformis KBR6) and two fungal (Penicillum spp., Aspergillus spp.) strains of our laboratory collection were used 
to detect their tanninolytic efficiency on newly formulated medium.

Dried fruits of bahera were collected, cleaned and grinded. Seed coat dust $(50 \mathrm{~g})$ were mixed with distilled water $(200 \mathrm{ml})$ and kept at room temperature overnight in continuous shaking. After soaking, the mixture was boiled for $10 \mathrm{~min}$. The filtered solutions were lyophilized to a powdered form which was used further as crude natural tannin (7). The medium used in the present study was supplemented with bahera tannin. The composition was as follows $\left(\mathrm{g} \mathrm{l}^{-1}\right)$ : tannic acid, 4.0; $\mathrm{NH}_{4} \mathrm{Cl}, 3.0$; $\mathrm{K}_{2} \mathrm{HPO}_{4}, 0.5 ; \mathrm{MgSO}_{4}, 0.5$; Glucose, 0.1 ; lyophilized bahera tannin, 1.0 and agar, 30.0. The $\mathrm{pH}$ of the medium was adjusted to $5.0 \pm 0.2$. Additions of bahera tannin impart a pale brown colour to the medium. After inoculation, a clear zone appeared around the tannase positive microbial colonies against the palebrown background after 12-16 hrs of incubation.

Methods described by Osawa and Walsh (18), Mondal and Pati (15), Kumar et al., (12) and newly formulated media were compared for the plate screening efficiency. That is why, different samples like sal forest soil, forest litter, decaying bark/ wood and tannary effluent were used and tanninolytic microbial count was determined through spread plate technique. The load was expressed in colony forming unit of bacteria and fungi present in per gram of sample $\left(\mathrm{cfu} \mathrm{g}^{-1}\right)$.

According to visual reading method of Osawa and Walsh (18), the cell free fermented broth was alkalinized with equal amounts of saturated $\mathrm{NaHCO}_{3}$ solution $(\mathrm{pH}$ 8.6) and then kept at room temperature $\left(23^{\circ} \mathrm{C}\right)$ for $1 \mathrm{~h}$. The medium was colored into brown from green. Absorption above 0.500 ( $\lambda \max , 440)$ was considered as tannase- positive culture. But the major limitation is that this method is specific for only bacteria. Recently Kumar et al., (12) used a combination of nutrient agar and tannic acid for the growth and selective isolation of tannase producing bacteria. After development, a staining technique was employed for clear clarity of halo-tannin zone. But the use of nutrient broth [containing beef extract $(0.3 \% \mathrm{w} / \mathrm{v})$, bacteriopeptone $(0.5 \% \mathrm{w} / \mathrm{v})]$ in detection of tannin hydrolysis seriously limits its utilization only by the members of Enterobacteriaceae and Staphylococcus family $(11,17)$. The proteins present in the medium form complexes with tannic acid (14). Another problem is that as microbes are able to degrade the tannic acidnutrient broth protein complexes, they have tendency to produce proteases simultaneously $(1,18)$ in the same medium which will seriously compromise with the tannase stability (1).

As commercial tannic acid is a costly substrate; a lot of researchers have utililized natural tannin rich agroindustrial residues for the production of tannase, gallic acid and other side products (7). Hota et al., (8) reported about the gallic acid production using tannin-rich agro-residues comprising sal seed (Shorea robusta), myrobalan fruit (Terminalia chebula,) and tea leaf (Camellia sinensis) through immobilization. Selwal et al., (21) optimized the production of extracellular tannase on natural tannin obtained from fruit of Terminalia chebula. Likewise, many researchers have met the production optimization using natural tannin-rich agro-residual substrates. Hence, we planned to use the natural tannins in the early stage of scale-up process i.e., in the laboratory screening processes, which will make the isolation process accurate.

In the present method, we have used a foremost plant tannin powder which was extracted from Terminalia belerica Roxb. (bahera) for the selective isolation of tanninolytic microbes. Bahera tannin extract itself contains gallic acid, ellagic acid and some sorts of sugars that help microorganisms grow faster. With that, the extract contains a specific chromogen of blackish brown colour which disappears completely after tannin hydrolysis (19) resulting in development of a clear halo zone around the colonies of representative strains of bacteria (Bacillus sp. PAB2 and Bacillus licheniformis KBR6), fungi (Penicillum spp. and Aspergillus spp.) and enteric yeasts (Figure 1). Such development was faster in case of fungi (on and around $12 \mathrm{hrs}$ of incubation) than bacteria (taking nearly $20 \mathrm{hrs}$ ). Unlike Kumar et al., (12) the method does not need additional staining procedure. Therefore, the method employed in the present 
study could detect tannase producing microbes from a mixed population within a short incubation period. The method is also sensitive for those organisms which produce very low amounts of tannase. Furthermore, it is cheaper, faster, reliable and reproducible.

A comparative account of four screening methods [viz. visual reading method of Osawa and Walsh (18), commercial tannic acid method of Mondal and Pati (15), nutrient agartannic acid method of Kumar et al., (12) and the present method of bahera tannin] was done to explore the best tannin degrading efficacy using different samples like sal forest soil, forest litter, decaying bark/ wood, tannary effluent, human feces, cow dung, etc. It was found that tannase producing bacteria, yeast and fungi were developed with highest efficiency in the newly formulated media (Table 1) than others.

Thus, the use of bahera tannin in selective isolation of tannase producing microbes is hence promising as it was exploited from the results of newly formulated method. The method is very simple to perform, sensitive and reproducible and requires a short incubation time as compared to other existing methods. So, the method will be very useful for the primary screening of tanninolysis and can be included as a conventional biochemical test in the classical identification system.
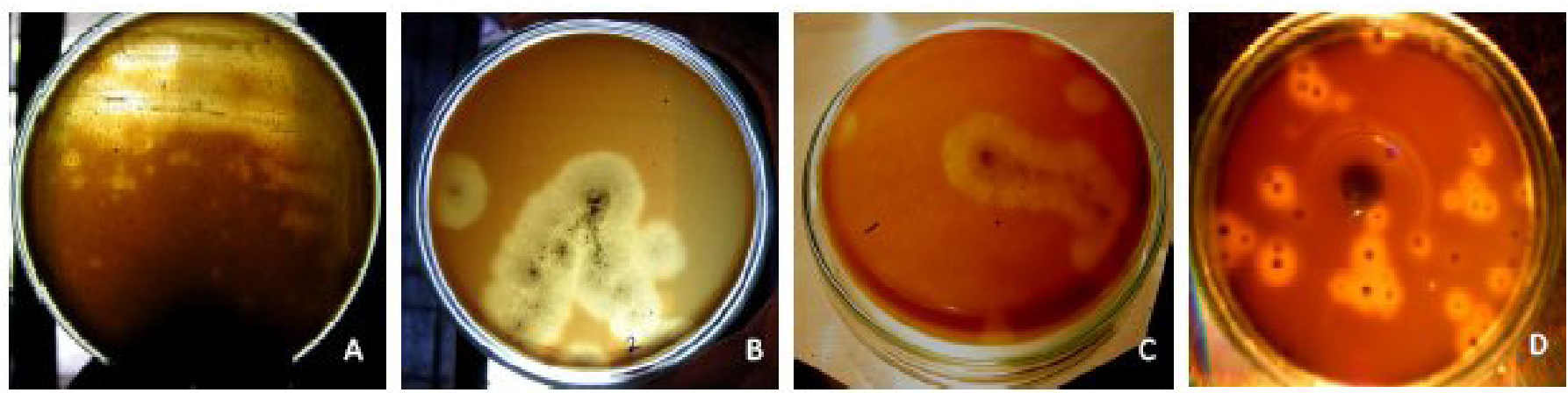

Figure 1. Formation of clear halo zone from tanninolysis around the microbial colonies on the surface of newly formulated differential medium containing tannin of Terminalia belerica Roxb. seed coat against a dark background [Bacillus licheniformis KBR 6 (A), Penicillium sp. (B), Aspergillus sp. (C) and enteric yeast (D)].

Table 1. Comparison between newly formulated media formed from five sources and three other previously reported procedures with regard to tanninolytic microbial count.

\begin{tabular}{lcccc}
\hline Sample Name & & \multicolumn{2}{c}{ Microbial load (cfu g $\mathbf{~}^{-\mathbf{1}}$ ) } \\
& Osawa and Walsh (16) & Mondal and Pati (14) & Kumar et al., (11) & Newly formulated medium \\
\hline Sal forest soil & $3(0) \pm 1$ & $2(98) \pm 1$ & $1(0) \pm 2$ & $7(93) \pm 2$ \\
Forest litter & $2(0) \pm 1$ & $7(39) \pm 2$ & $3(0) \pm 2$ & $7(93) \pm 3$ \\
Tannery & $0(0) \pm 2$ & $4(96) \pm 2$ & $0(0) \pm 0$ & $2(98) \pm 1$ \\
effluent & $2(0) \pm 3$ & $6(94) \pm 4$ & $6(0) \pm 3$ & $5(95) \pm 3$ \\
Human feces & $2(0) \pm 1$ & $5(95) \pm 2$ & $1(0) \pm 3$ & $4(96) \pm 2$ \\
Cow dung & & & \\
\hline
\end{tabular}

Bacterial counts are at outside of the parenthesis and fungal counts are at inside. Numbers are the mean value of three replicates and represented with standard deviation ( \pm SD). 


\section{ACKNOWLEDGEMENTS}

1. Aguilar, C.N.; Gutierrez-Sanchez, G. (2001). Review: sources, properties, applications and potential uses of tannin acyl hydrolase. Food Sci. Tech. Int., 7, 373-382.

2. Aoki, K.; Tanaka, T.; Shinke, R.; Nishira, H. (1979). Detection of tannase in polyacrylamide gels. J. Chromatogr., 17, 446-448.

3. Bajpai B.; Patil S. (2008). A new approach to microbial production of gallic acid. Braz. J. Microbiol., 39, 708-711.

4. Bhat, T.K.; Singh, B.; Sharma, O.P. (1998). Microbial degradation of tannins - A current perspective. Biodegradation., 9, 343-357.

5. Chae, S.K.; Yu, T.J. (1983). Experimental manufacture of acron wine by fungal tannase. Hanguk Sipkum Kwahakhoechi., 15, 326-332.

6. Coggon, P.; Sanderson, G.W. (1972). Manufacture of instant tea. Patent Ger. offen 2.304073 (cl. A. 23f.) 16 August 1973.

7. Das Mohapatra, P.K.; Mondal, K.C.; Pati, B.R. (2006). Production of tannase through submerged fermentation of tannin-containing plant extracts by Bacillus licheniformis KBR6. Pol. J. Microbiol., 55, 297301.

8. Hota, S.K.; Ray Dutta, J.; Banerjee, R. (2007). Immobilization of tannase from Rhizopus oryzae and its efficiency to produce gallic acid from tannin rich agro-residues. Indian J. Biotechnol., 6, 200-204.

9. Iibuchi, S.; Minoda, Y.; Yamada, K. (1967). Studies on tannin acy hydrolase. Part II. A new method determining the enzyme activity using the change of ultraviolet absorption. Agric.Biol. Chem., 31, 513-518.

10. Jean, D.; Pourrat, H.; Pourrat, A.; Carnat, A. (1981). Assay of tannase (tannin acyl hydrolase E.C. 3.1.1.20) by gas chromatography. Anal. Biochem., 110, 369-372.

11. Karlsson, A.; Arvidson, S. (2002). Variation in extracellular protease production among clinical isolates of Staphylococcus aureus due to different levels of expression of the protease repressor sarA. Infect. Immun., 70, 4239-4246.
12. Kumar, R.; Kumar, A.; Nagpal, R.; Sharma, J.; Kumari, A. (2010). A novel and sensitive plate assay for screening of tannase-producing bacteria. Ann. Microbiol., 60,177-179.

13. Lekha, P.K.; Lonsane, B.K. (1997). Production and application of tannin acyl hydrolase: state of the art. Adv Appl Microbiol., 44, 215-260.

14. Maity, C.; Das Mohapatra, P.K.; Pati, B.R.; Mondal, K.C. (2009). A simple gel detection method of microbial tannin acyl hydrolase (EC 3.1.1.20). World J. Microbiol. Biotechnol., 25, 725-733.

15. Mondal, K.C.; Pati, B.R. (2000). Studies on the extracellular tannase from newly isolated Bacillus licheniformis KBR6. J. Basic Microbiol., 40, 223-232.

16. Murugan K.; Saravanababu S.; Arunachalam M. (2007). Screening of tannin acyl hydrolase (E.C.3.1.1.20) producing tannery effluent fungal isolates using simple agar plate and SmF process. Bioresource Technol., 98, 946-949.

17. Noguchi N.; Ohashi T.; Shiratori T.; Narui K.; Hagiwara T.; Ko M.; Watanabe K.; Miyahara T.; Taira S.; Moriyasu F.; Sasatsu M. (2007) Association of tannase-producing Staphylococcus lugdunensis with colon cancer and characterization of a novel tannase gene. $J$. Gastroenterol., 42, 346-351.

18. Osawa, R.; Walsh, T.P. (1993). Visual reading method for detection of bacterial tannase. Appl. Environ. Microbiol., 59, 1251-1252.

19. Patil, D. B.; Das, S. K.; Das Mohapatra P. K.; Nag, A. (2011). Physicochemical studies and optimization of gallic acid production from the seed coat of Terminalia belerica Roxb. Ann Microbiol., DOI 10.1007/s13213-010-0185-2, 61, 649-654.

20. Pinto, G.A.S.; Leite, S.G.F.; Terzi, S.C.; Couri, S. (2001). Selection of tannase-producing Aspergillus niger strains. Braz. J. Microbiol., 32, 2426.

21. Selwal M.K.; Yadav A.; Selwal K.K.; Aggarwal N.K.; Gupta R.; Gautam S.K. (2011). Tannase production by Penicillium atramentosum KM under SSF and its application in wine clarification and tea cream solubilization. Braz. J. Microbiol., 42, 374-387. 